\title{
The Roles of UmuD in Regulating Mutagenesis
}

\author{
Jaylene N. Ollivierre, ${ }^{1}$ Jing Fang, ${ }^{1}$ and Penny J. Beuning ${ }^{1,2}$ \\ ${ }^{1}$ Department of Chemistry and Chemical Biology, Northeastern University, 360 Huntington Avenue, 102 Hurtig Hall, \\ Boston, MA 02115, USA \\ ${ }^{2}$ Center for Interdisciplinary Research on Complex Systems, Northeastern University, 360 Huntington Avenue, 102 Hurtig Hall, \\ Boston, MA 02115, USA
}

Correspondence should be addressed to Penny J. Beuning, beuning@neu.edu

Received 13 June 2010; Accepted 1 August 2010

Academic Editor: Ashis Basu

Copyright (c) 2010 Jaylene N. Ollivierre et al. This is an open access article distributed under the Creative Commons Attribution License, which permits unrestricted use, distribution, and reproduction in any medium, provided the original work is properly cited.

\begin{abstract}
All organisms are subject to DNA damage from both endogenous and environmental sources. DNA damage that is not fully repaired can lead to mutations. Mutagenesis is now understood to be an active process, in part facilitated by lower-fidelity DNA polymerases that replicate DNA in an error-prone manner. Y-family DNA polymerases, found throughout all domains of life, are characterized by their lower fidelity on undamaged DNA and their specialized ability to copy damaged DNA. Two E. coli Y-family DNA polymerases are responsible for copying damaged DNA as well as for mutagenesis. These DNA polymerases interact with different forms of UmuD, a dynamic protein that regulates mutagenesis. The UmuD gene products, regulated by the SOS response, exist in two principal forms: $\mathrm{UmuD}_{2}$, which prevents mutagenesis, and $\mathrm{UmuD}_{2}^{\prime}$, which facilitates $\mathrm{UV}$-induced mutagenesis. This paper focuses on the multiple conformations of the UmuD gene products and how their protein interactions regulate mutagenesis.
\end{abstract}

\section{Mutagenesis Due to Y-Family DNA Polymerases}

The observation of nonmutable phenotypes of E. coli umu (UV-nonmutable) mutants led to the discovery that mutagenesis in E. coli is an active process [1-4]. The mutagenesis process utilizes specialized DNA polymerases belonging to the Y family [5]. Y-family DNA polymerases are found in all domains of life and have the specialized ability to replicate damaged DNA, a process known as translesion synthesis (TLS) [5-8]. This specialized ability comes at the cost of lower fidelity in replicating undamaged DNA compared to replicative DNA polymerases. Indeed, Y-family polymerases are from one to several orders of magnitude less accurate than replicative DNA polymerases [9-11]. Moreover, Yfamily polymerases lack intrinsic $3^{\prime}-5^{\prime}$-exonuclease activity and have inherent low processivity $[6,8,12-14]$. Because the cellular functions of Y-family DNA polymerases are potentially mutagenic, their activities are tightly regulated. E. coli has two members of the $\mathrm{Y}$ family, DNA pol IV (DinB, encoded by the $\operatorname{dinB}$ gene) [15] and pol V (UmuD ${ }_{2}^{\prime} \mathrm{C}$, encoded by the UmuD and UmuC genes) [16, 17], whose functions are regulated on multiple levels. A key feature of their regulation is their interactions with products of the UmuD gene.

\section{SOS Regulation}

The UmuD gene is found in an operon with $\operatorname{UmuC}[18,19]$. The expression of these genes, as well as the $\operatorname{din} B$ gene, is negatively regulated by the LexA repressor as part of the SOS response $[7,20]$. LexA binds to a sequence in the operator region of regulated genes called the "SOS box," with a consensus sequence of $5^{\prime}$ taCTGtatatataCAGta, where the most conserved residues are in capital letters [21]. Upon DNA damage, a region of single-stranded DNA (ssDNA) forms due to the inability to continue replication of the damaged DNA. RecA polymerizes on the ssDNA, forming a RecA/ssDNA nucleoprotein filament, which is the inducing signal for the SOS response (Figure 1) [22]. Upon binding to the RecA/ssDNA filament, LexA undergoes a conformational change that stimulates its latent ability to cleave itself [23]. LexA cleavage inactivates it as a repressor and exposes a 


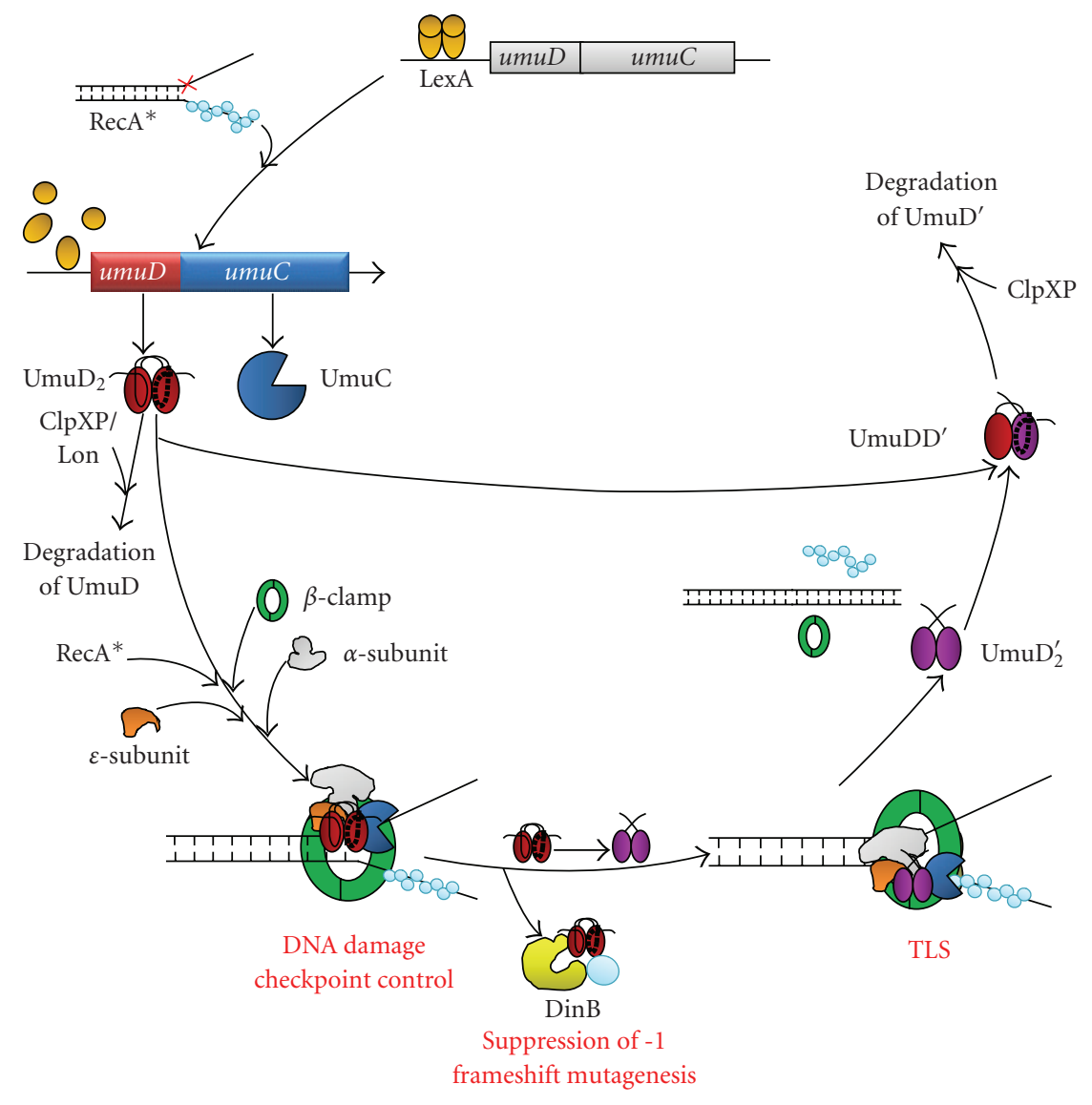

Figure 1: Life cycle and interactions of UmuD gene products. Details are described in the text.

proteolysis signal sequence, leading to degradation of LexA [24] and to increased expression of at least 57 SOS-regulated genes, including UmuD [20]. The cellular levels of UmuD, UmuC, and DinB all increase approximately 10-fold upon SOS induction, with UmuD increasing from $\sim 180$ to $\sim 2400$ molecules, UmuC increasing from $\sim 15$ to $\sim 200$ molecules, and DinB increasing from $\sim 250$ to $\sim 2500$ molecules per cell $[25,26]$. The products of SOS-regulated genes are involved in DNA repair, DNA damage tolerance, and regulation of cell division. As the cell recovers from genotoxic stresses, it is presumed that the concentration of ssDNA is reduced, resulting in a decrease of RecA/ssDNA filament in the cell. This occurrence allows intact LexA to accumulate, thereby diminishing the SOS response [4].

\section{UmuD is a Molecular Adaptor That Regulates Mutagenesis}

Following initiation of the SOS response, $\mathrm{UmuD}_{2}$ is the predominant form of the protein for 20-30 minutes [27]. The presence of UmuD and UmuC protects the cell from the potential deleterious effects of the error-prone DNA damage response pathway, a function which is genetically distinct from their role in SOS mutagenesis $[27,28]$. $\mathrm{UmuD}_{2}$, together with UmuC, may act in a primitive DNA damage checkpoint, as they specifically inhibit DNA replication without an effect on transcription or translation when present at elevated levels in cells grown at $30^{\circ} \mathrm{C}[27,29]$. UmuD and UmuC also slow the resumption of DNA replication after UV irradiation [27]. Therefore, UmuDC acts in a noncatalytic fashion by delaying SOS mutagenesis and thereby allowing accurate pathways such as nucleotide excision repair time to proceed $[27,28]$. Moreover, UmuD interacts with DinB and inhibits its mutagenic -1 frameshift activity [30].

$\mathrm{UmuD}_{2}$ interacts with the RecA/ssDNA filament, which stimulates the ability of UmuD to cleave itself, removing its $\mathrm{N}$-terminal 24 amino acids [31-33]. UmuD is homologous to the C-terminal domain of LexA, and their cleavage reactions are remarkably similar: both proteins utilize a SerLys (S60-K97 in UmuD) catalytic dyad, which is also similar to the reaction carried out by signal peptidases [34]. By analogy to signal peptidases, K97 is proposed to deprotonate S60, which is then capable of nucleophilic attack on the peptide backbone [34]. Therefore, $\mathrm{UmuD}_{2}$ and LexA also undergo autodigestion at elevated $\mathrm{pH}[23,33]$. The kinetics of cleavage are remarkably different for $\mathrm{UmuD}_{2}$ and LexA, with cleavage of LexA much more efficient than that of $\mathrm{UmuD}_{2}$ in both RecA- and alkaline-mediated cleavage [33]. Moreover, LexA undergoes intramolecular cleavage [35] while $\mathrm{UmuD}_{2}$ is capable of intermolecular cleavage [3638]. 


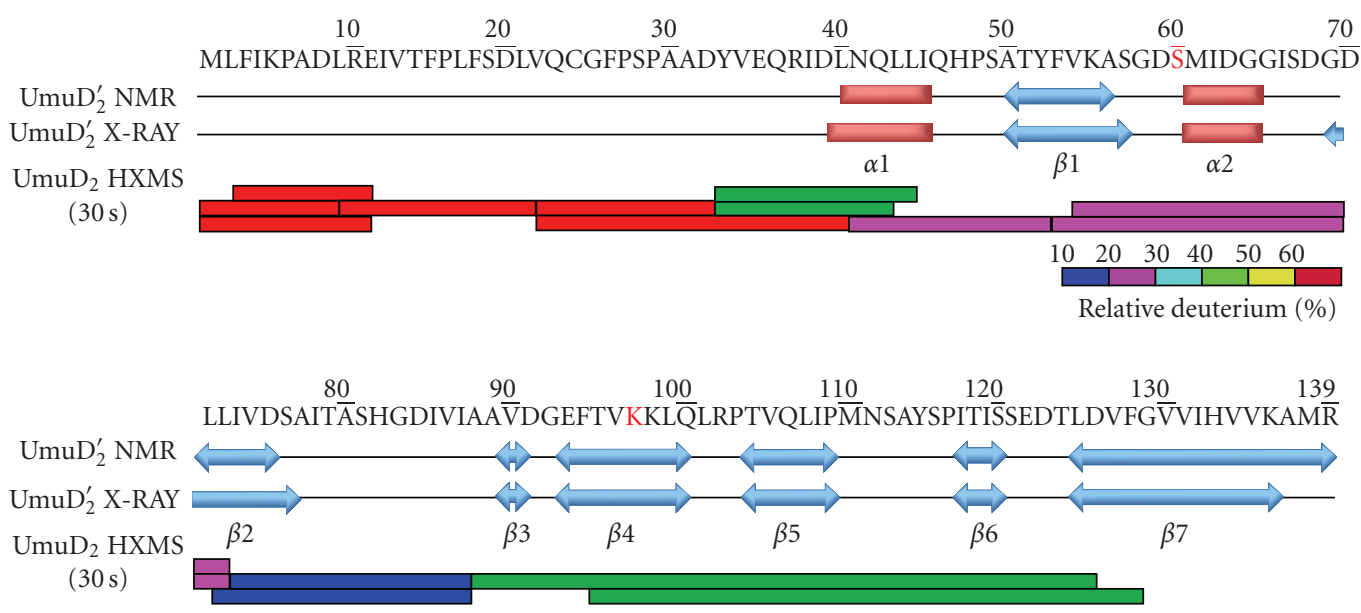

(a)

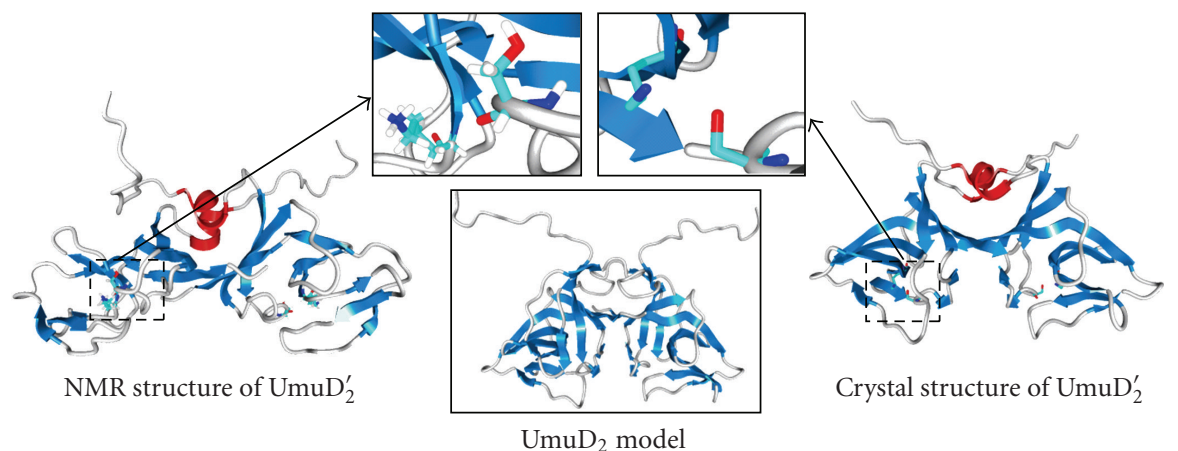

(b)

Figure 2: The secondary and tertiary structure of $\mathrm{UmuD}_{2}$ and $\mathrm{UmuD}_{2}^{\prime}$. (a) Secondary structure comparison between the UmuD $\mathrm{N}_{2}^{\prime} \mathrm{NMR}$ $[44,45]$ and crystal [46] structures. The $\alpha$ helices are shown in red, and $\beta$ sheets are shown in blue. Relative deuterium incorporation of $\mathrm{UmuD}_{2}$ at $30 \mathrm{sec}$ labeling in HXMS experiments is shown, and the colors are based on the relative deuterium percentage scale shown [51]. (b) Comparison of the $\operatorname{NMR}[44,45]$ and crystal [46] structures of $\mathrm{UmuD}_{2}^{\prime}$. The color of the $\alpha$ helices and $\beta$ sheets is consistent with (a). The active site regions are boxed and shown in the insets. A model of full-length $\mathrm{UmuD}_{2}$ is shown [52].

RecA-facilitated cleavage of UmuD to UmuD' occurs 20 40 minutes after the induction of SOS and serves to initiate TLS $[4,27]$. UmuD' together with UmuC forms the TLS polymerase Pol $\mathrm{V}$ that is active in the damage tolerance mechanism SOS mutagenesis $[4,16,17,39,40]$. Additionally, $\mathrm{UmuD}^{\prime}$ and UmuC inhibit RecA-dependent homologous recombination as a result of the direct interaction of $\mathrm{UmuD}^{\prime} \mathrm{C}$ with the RecA/ssDNA nucleoprotein filament, thereby preventing accurate recombination repair [41-43]. Taken together, these results support a model in which fulllength UmuD acts to prevent mutagenesis while $\mathrm{UmuD}^{\prime}$ facilitates it.

\section{Structure and Dynamics of UmuD}

Since the UmuD gene products play crucial roles in managing the biological responses to DNA damage, the conformation and dynamics of $\mathrm{UmuD}_{2}$ and $\mathrm{UmuD}_{2}^{\prime}$ are of great interest. To date, the structure of full-length $\mathrm{UmuD}_{2}$ has not been amenable to crystallization or NMR analysis.
However, the NMR [44, 45] and crystal [46] structures (Figure 2) of $\mathrm{UmuD}_{2}^{\prime}$ have been solved. Both structures show that $\mathrm{UmuD}_{2}^{\prime}$ is a homodimer with a $\mathrm{C}_{2}$ axis of symmetry and show similar secondary structures: $\mathrm{UmuD}_{2}^{\prime}$ is composed primarily of $\beta$-strands with two short $\alpha$-helices in each monomer. The C-terminal globular domain (residues 40 139 ) is mainly composed of curved antiparallel $\beta$-strands connected by tight turns with a long C-terminal strand, $\beta 7$, that spans both monomers (Figure 2). Residues between positions 132-139 in $\beta 7$ in UmuD and $\mathrm{UmuD}^{\prime}$ show the strongest interdimer cross-linking of their monocysteine derivatives [47]. The $\alpha 1$ helices pack against each other in the dimer interface. Both $\mathrm{UmuD}_{2}$ and $\mathrm{UmuD}_{2}^{\prime}$ are exceptionally tight dimers with equilibrium dissociation constants $K_{\mathrm{D}^{\mathrm{s}}}<$ $10 \mathrm{pM}$ [48]. The active site residue K97 is in the middle of strand $\beta 4$ while $S 60$ is in helix $\alpha 2$ (Figure 2) $[44,46]$. In both structures, the short N-terminal arms that remain after cleavage (residues 25-39) are largely unstructured $[45,46]$.

The differences between the X-ray and NMR structures of $\mathrm{UmuD}^{\prime}$ are not insignificant [44]. The RMSD of the backbone atoms (residues 40-139) between the two 


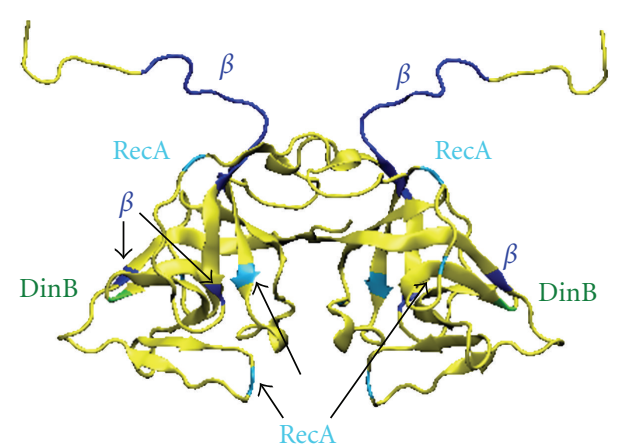

(a)

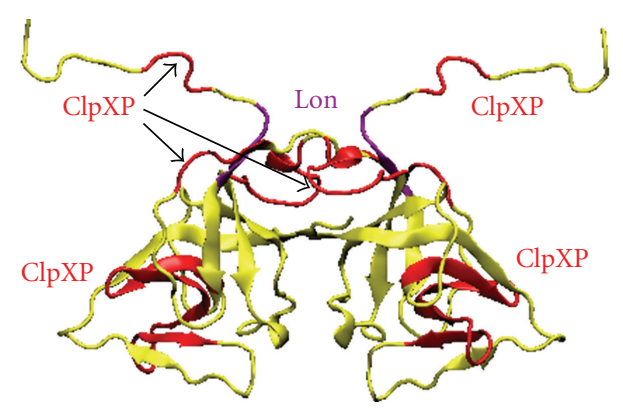

(b)

Figure 3: Protein interaction sites on UmuD. (a) The $\beta$ clamp interacts with residues $14-19,24,52$, and 126 (blue) [53]. RecA interacts with residues $34,81,57,67$, and 112 (cyan) [49]. DinB interacts with residue 91 on UmuD (green) [30]. (b) ClpXP interacts with residues 9-12, 33-37, 41-51, and 85-109 (red) [123]. Lon binds to regions close to the residues that are important for interaction with ClpXP, residues 15-19 (violet) [125].

structures of $\mathrm{UmuD}_{2}^{\prime}$ is $4.59 \AA$ [44]. Moreover, the active site in the crystal structure appears correctly positioned for catalysis, while in the NMR structure, the catalytic residues Ser60 and Lys97 are over $7 \AA$ apart and are not positioned appropriately (Figure 2) $[44,46]$. It has been suggested that the conformation of $\mathrm{UmuD}_{2}^{\prime}$ in the crystal structure is similar to the conformation of $\mathrm{UmuD}_{2}$ bound to the RecA/ssDNA nucleoprotein filament [44], which might indicate the mechanism whereby RecA/ssDNA acts as a coprotease in facilitating UmuD cleavage. Several residues on the outer loops and the surface of $\mathrm{UmuD}_{2}$, specifically Val34, Ser57, Ser67, Ser81, and Ser112, each when changed to single cysteines, have been shown to cross-link to RecA and therefore are likely sites of interaction between the two proteins (Figure 3) [49]. The structure of $\mathrm{UmuD}_{2}^{\prime} \mathrm{C}$ RecA/ssDNA complex determined by using cryo-electron microscopy shows $\mathrm{UmuD}_{2}^{\prime} \mathrm{C}$ bound deep in the groove of the RecA/ssDNA nucleoprotein filament and a second binding mode with $\mathrm{UmuD}_{2}^{\prime} \mathrm{C}$ at the end of the RecA/ssDNA filament [50].

The differences in the X-ray and NMR structures of $\mathrm{UmuD}^{\prime}$ and other findings suggested that UmuD and $\mathrm{UmuD}^{\prime}$ may be quite dynamic proteins. Indeed, $\mathrm{UmuD}_{2}$ and $\mathrm{UmuD}_{2}^{\prime}$ were recently found to be intrinsically disordered proteins [48]. Despite the predominantly $\beta$-sheet character in the solved structures of UmuD', the circular dichroism spectra of both UmuD' and UmuD at physiological concentrations $(5 \mu \mathrm{M})$ in solution are more characteristic of a random coil than of $\beta$ sheets [48]. Higher concentrations of UmuD or UmuD' $(2 \mathrm{mM})$ or incubation with crowding agents or partner proteins including $\operatorname{DinB}$ or the $\beta$ clamp induced CD spectra more characteristic of a predominantly $\beta$-sheet structure [48].

An analysis of the dynamics of UmuD using hydrogendeuterium exchange mass spectrometry (HXMS) found that many regions of $\mathrm{UmuD}_{2}$ were highly dynamic in solution, especially its N-terminal arms (Figure 2), consistent with previous suggestions $[36,44,51]$. In addition, the comparison of the conformations and dynamics of $\mathrm{UmuD}_{2}$ and $\mathrm{UmuD}_{2}^{\prime}$ in solution by HXMS indicated that the $\mathrm{N}$ terminal arm was a key factor governing the dynamics of $\mathrm{UmuD}_{2}$ and $\mathrm{UmuD}_{2}^{\prime}$. In the absence of the N-terminal 24 residues in $\mathrm{UmuD}_{2}^{\prime}$, regions of the globular domain likely to contact the arm underwent more exchange than in $\mathrm{UmuD}_{2}$ [51]. The predicted dimer interface of $\mathrm{UmuD}_{2}$ was the most resistant to deuteration indicating that this region is the most stable and structured part of the protein. The results of HXMS were consistent both with the proposed model of $\mathrm{UmuD}_{2}$ [52] and with the observation that $\mathrm{UmuD}_{2}$ is relatively unstructured [48].

Gas-phase hydrogen-deuterium exchange experiments, which specifically detect side-chain hydrogen exchange at msec time scales, show that when the arm is truncated, in $\mathrm{UmuD}_{2}^{\prime}$, more side-chain sites can be labeled, reinforcing the idea that the arm protects part of the globular domain of the protein from interactions with solvent [51]. Therefore, the flexible $\mathrm{N}$-terminal arm and the extended binding interface are potential sites for $\mathrm{UmuD}_{2}$ to interact with other partner proteins. Indeed, the $\beta$ processivity clamp has been shown to interact with specific amino acids in both the $\mathrm{N}$-terminal arm and the globular domain of $\mathrm{UmuD}_{2}$ [53].

Also in support of the dynamic nature of UmuD, it was found that Leu101 and Arg102 are important for proper positioning of the Ser/Lys active site dyad upon interaction with the RecA/ssDNA filament [54]. HXMS experiments showed that the peptides including these residues (89125 and 95-128) are highly deuterated (Figure 2) [51]. Additionally, from molecular modeling experiments four distinct conformations of $\mathrm{UmuD}_{2}$ were calculated; all four were isoenergetic, suggesting that all four conformations may be physiologically relevant [52]. Thus, the flexibility of $\mathrm{UmuD}_{2}$ is likely to be a key feature governing its cleavage activity as well as interactions with its numerous protein partners.

Not only are the monomer units of UmuD and UmuD' highly flexible, but multiple dimeric forms are also observed. Homodimers of $\mathrm{UmuD}_{2}$ and $\mathrm{UmuD}_{2}^{\prime}$ readily exchange to form the UmuDD' heterodimer, which has been found to be the most thermodynamically stable dimeric form [55]. Additionally, the X-ray structure of $\mathrm{UmuD}_{2}^{\prime}$ suggested two possible dimer interfaces $[46,56]$. Much biochemical data, as well as solution NMR and HXMS experiments, are consistent with the dimer interface shown in Figure $2[45,47,51]$. However, some experiments suggest that the other dimer 
interface (not shown) may also form [56]. Both dimer interfaces may be present in solution, as indicated by the observation of higher order cross-linked UmuD multimers of molecular weights consistent with tetramers and hexamers and larger complexes $[28,56]$. UmuD and UmuD' appear to be intrinsically highly dynamic proteins that can adopt multiple dimeric, and possibly higher order, forms.

\section{The Interactions of the UmuD Gene Products with the $\alpha, \beta$, and $\varepsilon$ Subunits of DNA Polymerase III}

DNA pol III is the 10-subunit complex responsible for most DNA replication in E. coli $[57,58]$. Although pol III and $\mathrm{UmuD}_{2}^{\prime} \mathrm{C}$ reduce the primer extension activity of each other by competing for DNA primer termini, they also appear to directly interact as $\mathrm{UmuD}_{2}^{\prime} \mathrm{C}$ enhances the polymerase activity of pol III with a temperature-sensitive $\alpha$ protein in vitro $[17,59,60]$. $\mathrm{UmuD}_{2}$ and $\mathrm{UmuD}_{2}^{\prime}$ directly interact with components of the replicative DNA polymerase III, including the $\alpha$ catalytic, $\beta$ processivity, and $\varepsilon$ proofreading subunits $[28,61]$. The UmuD gene products display differential interactions with these components of the replisome. $\mathrm{UmuD}_{2}$ binds more strongly to the $\beta$ processivity clamp than $\mathrm{UmuD}_{2}^{\prime}$ does whereas $\mathrm{UmuD}_{2}^{\prime}$ binds more strongly to the $\alpha$ polymerase subunit than $\mathrm{UmuD}_{2}$ does, which is consistent with the UmuD gene products serving temporally separate roles in coordinating the replication machinery in response to DNA damage [61].

The $\varepsilon$ subunit possesses $3^{\prime}$ to $5^{\prime}$ exonuclease activity and serves as the proofreading subunit of the replicative DNA polymerase [57]. Both $\mathrm{UmuD}_{2}$ and $\mathrm{UmuD}_{2}^{\prime}$ interact with the C-terminal domain of $\varepsilon$, which is the same region of $\varepsilon$ that contacts $\alpha$ [61-63]. The overexpression of the $\varepsilon$ subunit suppresses UmuDC-mediated cold sensitivity whereas overexpression of any of the other pol III subunits does not [62].

By far, the best characterized interactions of UmuD or $\mathrm{UmuD}^{\prime}$ with the replisome are the interactions between UmuD or UmuD' and the $\beta$ processivity clamp. Overexpression of the $\beta$ processivity clamp exacerbates UmuDCmediated cold sensitivity, which was used as the basis of selection to identify additional sites of interaction between UmuD', UmuC, and the $\beta$ clamp $[62,64,65]$. It was suggested that the exacerbation of the cold sensitive phenotype is due to an exaggerated checkpoint response $[61,64]$.

$\mathrm{UmuD}_{2}$ binds to $\beta$ in the vicinity of the same hydrophobic pocket region where other $\beta$-binding proteins interact $[53,66]$. As the $\beta$ clamp is a homodimer, it has two such interaction sites per functional protein. However, there is still likely to be a hierarchy or competition for binding to the clamp because at least eight proteins are likely to interact with the $\beta$ clamp at the same site, some of which possess different affinities for the $\beta$ clamp (Table 1) [6674]. By using site-directed mutagenesis and cross-linking experiments, it was reported that $\mathrm{UmuD}_{2}, \mathrm{UmuD}_{2}^{\prime}$, and the $\alpha$ catalytic subunits of Pol III share some common contacts with $\beta$, but each of these proteins possesses a different
TABle 1: E. coli proteins that interact with the $\beta$ clamp via the $\beta$ binding pentapeptide motif QL[SD]LF or similar sequence [67].

\begin{tabular}{lcc}
\hline$\beta$-interacting proteins & $\beta$-binding sequence & References \\
\hline UmuD & ${ }^{14}$ TFPLF $^{18}$ & {$[52,53]^{(1)}$} \\
DNA Pol V (UmuC) & ${ }^{357}$ QLNLF $^{361}$ & {$[127,128]$} \\
DNA Pol IV (DinB) & ${ }^{346}$ QLVLGL $^{351}$ & {$[68,127,129]$} \\
DNA Pol II (Pol B) & ${ }^{779}$ QLGLF $^{783}$ & {$[127]$} \\
DNA Pol III ( $\alpha$-subunit) & ${ }^{920} \mathrm{QADMF}^{924}$ & {$[130]$} \\
$\delta$-subunit Clamp Loader & ${ }^{70} \mathrm{AMSLF}^{74}$ & {$[131]$} \\
MutS & ${ }^{812} \mathrm{QMSLL}^{816}$ & {$[132]$} \\
Hda & ${ }^{6} \mathrm{QLSLPL}^{11}$ & {$[133]$} \\
\hline
\end{tabular}

(1) Although these residues reside in an important region for interactions with the $\beta$ clamp, their identity is not required for UmuD to interact with $\beta$ (see text Section 5).

affinity for $\beta$ [66]. The $\mathrm{N}$-terminal region of $\mathrm{UmuD}_{2}$ contains a canonical $\beta$ clamp-binding motif $\left({ }^{14}\right.$ TLPLF $^{18}$ ) (Figures 2 and 3 , Table 1); this motif is used by a number of proteins to bind to the hydrophobic pocket on the $\beta$ clamp (Figure 3) [67]. By constructing truncations of UmuD, it was determined that the residues between 9 and 19 are critical for interactions with the $\beta$ clamp [53]. $\mathrm{A} \mathrm{UmuD}_{2}$ variant containing mutations in the canonical $\beta$ clamp interaction motif was found to bind $\beta$ with the same affinity as wild-type UmuD but with a different tryptophan fluorescence emission spectrum of $\beta$ [52], which indicates that the motif itself is not necessary for the interaction, but it likely indicates a conformational change in the $\beta$ clamp upon UmuD binding [6]. Additionally, residues in the C-terminal globular domain of UmuD and UmuD' are also involved in interactions with the $\beta$ clamp (Figure 3) [53]. Therefore, $\mathrm{UmuD}_{2}$ interacts with the $\beta$ clamp by both its $\mathrm{N}$-terminal arm and C-terminal globular domain.

\section{Molecular Interactions of UmuD with Y-Family DNA Polymerases UmuC and DinB}

6.1. Molecular Interactions of umuD Gene Products with UmuC. Disruptions to the umuDC operon result in nonmutability by UV, 4-nitroquinoline 1-oxide (4-NQO), methyl methanesulfonate (MMS), and other agents [1-4], presumably due to the lack of TLS by pol V. Pol V has a base substitution error frequency of $10^{-3}-10^{-5}$ on undamaged DNA, compared to $10^{-4}-10^{-6}$ for the replicative DNA polymerase pol III $[75,76]$. Pol V copies DNA-containing lesions such as abasic sites, thymine-thymine cyclobutane pyrimidine dimers, (6-4) photoproducts, as well as the $C^{8}$ dG adduct of $\mathrm{N}$-2-acetylaminofluorene, while preferentially misincorporating $\mathrm{dG}$ opposite the $3^{\prime} \mathrm{T}$ of the thyminethymine (6-4) photoproducts $[16,17,59,75,77,78]$. This specific mutagenic bypass of the (6-4) photoproduct is a major contributor to the observed UmuC-dependent SOS mutagenesis [75, 79]. UmuC contains intrinsic DNA polymerase activity and is therefore capable of DNA synthesis on undamaged DNA, but TLS activity requires the formation of the UmuD' C complex and the presence of RecA $[16,80]$. 
Other cofactors, including SSB and the $\beta$ processivity clamp and clamp loader, also support TLS by pol V $[16,17,59,75$, 80-86].

Whereas UmuD' is required for TLS by UmuC, fulllength UmuD does not support TLS [16, 87]. Cells expressing $\mathrm{UmuD}$ and $\mathrm{UmuC}$ at elevated levels exhibit a cold sensitive for growth phenotype that is not yet well understood [29]. Full-length UmuD also plays a role together with UmuC in inhibiting the recovery of DNA replication after UV exposure [27]. Moreover, full-length UmuD that cannot be cleaved because it harbors the S60A active site mutation causes a dramatic reduction in UV-induced mutagenesis while UmuD'-S60A shows only a modest decrease in UV-induced mutagenesis [32]. Cells expressing UmuC together with noncleavable UmuD-S60A are sensitive to UV relative to cells expressing wild-type UmuD and $\mathrm{UmuC}$ but are resistant to killing by UV irradiation relative to cells that are $\triangle u m u D C$ $[27,52,55]$. Taken together, these findings suggest that fulllength UmuD specifically prevents mutagenesis, presumably at least in part by preventing UmuC from engaging in mutagenic TLS.

Due to the difficulty in acquiring large quantities of pure, active $\mathrm{UmuC}$ and pol V, protein interaction studies have been somewhat limited, especially considering that the UmuC gene was identified in the 1970s. However, the physical interaction between $\mathrm{UmuD}^{\prime}$ and $\mathrm{UmuC}^{\mathrm{C}}$ was confirmed using immunoprecipitation, yeast two-hybrid assay and glycerol gradient analysis $[88,89]$. Additionally, the interaction between full-length UmuD and UmuC was verified by using affinity chromatography and velocity sedimentation in glycerol gradients, but not immunoprecipitation from cell extracts [88]. From this, it was concluded that UmuC associates strongly with $\mathrm{UmuD}^{\prime}$ in vivo whereas, in vitro, UmuC interacts efficiently with both forms of the UmuD gene products [88]. The likely stoichiometry was determined to be one UmuC with either a dimeric UmuD or UmuD' [88]. UmuD and $\mathrm{UmuD}^{\prime}$ appear to interact with the Cterminus of UmuC, as a UmuC construct lacking its Cterminal 25 residues showed dramatically reduced binding to both $U m u D$ and $\mathrm{UmuD}^{\prime}$ [28]. In addition to the UmuD and $\mathrm{UmuD}^{\prime}$ homodimers, UmuC also interacts with the UmuDD' heterodimer, which acts to inhibit SOS mutagenesis, possibly by titrating out the dimeric $\mathrm{UmuD}^{\prime}$ species that is active in TLS [88-91].

6.2. Molecular Interactions of UmuD and DinB. The $\operatorname{din} B$ (damage-inducible) gene encoding DNA pol IV (DinB) was discovered in a screen using reporter fusions to identify DNA damage-inducible genes [92]. DinB (Pol IV) is the other Y-family lesion bypass polymerase in E. coli and is the only Y-family polymerase that is conserved throughout all domains of life $[5,15]$. The expression level of chromosomal DinB under DNA damaging conditions is 6-12 times higher than that of UmuC or PolB (DNA pol II) with about 2500 molecules of DinB in an SOS-induced cell [25]. DinB is also found on the recombinant $\mathrm{F}^{\prime}$ plasmid that was constructed to determine mutation spectra of specific revertible $l a c^{-}$alleles $[25,93]$. The expression level of DinB in an uninduced state from the $\mathrm{F}^{\prime}$ plasmid in E. coli strain CC108 is approximately 750 molecules, as compared to 250 molecules expressed from the chromosome in the absence of SOS induction [25]. DinB has a misincorporation error frequency of $10^{-3}-10^{-5}$ [94]. Unlike UmuD' $\mathrm{C}$, DinB elongates templates with bulged structures causing potentially deleterious 1 frameshift mutations $[95,96]$. It was also shown that DinB and its eukaryotic ortholog Pol $\kappa$ can accurately and efficiently perform TLS on templates containing $\mathrm{N}^{2}$ deoxyguanosine $\left(N^{2}-\mathrm{dG}\right)$ adducts, suggesting that these proteins are specialized for relatively accurate TLS over some $N^{2}$-dG adducts [97-99].

UmuD, UmuD', and RecA play important roles in the regulation of $\mathrm{Din} B$, and direct physical interactions between DinB and UmuD, UmuD', and RecA have been detected [30]. Although this may have initially seemed surprising, the expression levels of UmuD (180 molecules uninduced; 2400 molecules in SOS-induced cells) and DinB (250 molecules uninduced; 2500 molecules in SOS-induced cells) before and after SOS induction align $[25,26]$. The stoichiometry of the complex was found to be one $\operatorname{Din} B$ molecule to one $\mathrm{UmuD}_{2}$ dimer [30]. $\mathrm{DinB}$ and $\mathrm{UmuD}_{2}$ bind with a $K_{D}$ of $0.62 \mu \mathrm{M}$ [30]. It was also determined that $\mathrm{DinB}, \mathrm{RecA}$, and $\mathrm{UmuD}_{2}$ form a stable ternary complex under physiological conditions in vitro [30]. Genetic and biochemical analysis shows that full-length UmuD as well as the noncleavable UmuD variant UmuD S60A strongly inhibits the -1 frameshift mutator effect of DinB [30]. UmuD and UmuD' also inhibit DinB activity in adaptive mutagenesis [30]. Presteady-state kinetics experiments led to the proposal that DinB bound to DNA containing a repetitive sequence is in equilibrium between a template slipped conformation, which leads to frameshift mutagenesis and a nonslipped conformation [100]. UmuD appears to prevent DinB-dependent frameshift mutagenesis by favoring the nonslipped conformation upon binding to DinB [100]. UmuD also modulates DinB function by facilitating efficient extension of correctly paired primer termini while blocking extension of mismatched termini $[30,100]$.

Using peptide array mapping and structural homology models of both DinB and UmuD, it was proposed that UmuD interacts with several hydrophobic residues on the surface of DinB in the thumb and finger domains. DinB residue F172 in the thumb domain was identified as a likely site of interaction with UmuD. Indeed, DinB F172A has lower affinity for $\mathrm{UmuD}\left(K_{D}\right.$ reduced $\sim 56$-fold $)$ and exhibits less UmuD-dependent - 1 frameshift suppression in vivo and in vitro than wild-type DinB [30]. The DinB interacting surface on $\mathrm{UmuD}$ is a discontinuous surface when mapped onto a model of trans-UmuD [47, 52]. Alternatively, isoenergetic models of UmuD in which the $\mathrm{N}$-terminal arms are in a noncleavable conformation provide alternative interacting surfaces across the side of UmuD [52]. UmuD D91, on the outer surface of UmuD, was proposed as a likely residue to be important for interaction with DinB (Figure 3). UmuD D91A has reduced affinity for DinB ( $K_{D}$ reduced by over 24-fold) and dramatically reduced suppression of -1 frameshift mutagenesis compared to wild-type UmuD [30]. This suggests that there may be multiple biologically relevant 
conformations of UmuD that can interact with DinB or other polymerases $[48,51,52,101]$. These interactions may aid in the suppression of frameshift mutagenesis by blocking the open active site that is needed to elongate bulged templates $[13,14,30,102]$. By creating a ternary complex model of $\mathrm{DinB}, \mathrm{UmuD}_{2}$, and $\mathrm{RecA}$, it was suggested that $\mathrm{UmuD}_{2}$ and RecA work together in restricting the open active site of DinB thereby preventing - 1 frameshift mutagenesis on bulged templates $[30,100]$. Therefore, the presence of fulllength UmuD actually enhances accurate TLS by DinB while suppressing extension of bulged templates that would cause frameshift mutagenesis.

\section{Molecular Interactions of UmuD and UmuD' $^{\prime}$ with Lon and ClpXP Proteases}

Regulation of UmuD protein levels by ClpXP and Lon proteases is an important part of the SOS response to DNA damage. Proteolytic degradation of the UmuD gene products is involved in cessation of SOS mutagenesis $[4,103,104]$. ClpXP is composed of the ATP-dependent unfoldase ClpX hexamer and the double-ringed, 14-subunit serine protease, ClpP [105-109]. The domain structure of the Lon protease is quite similar in that it contains an ATPase domain, a sensor and substrate discrimination domain (SSD), and a protease domain [110]. The mechanism of degradation begins when ClpX unfolds the substrates using repeated cycles of ATP hydrolysis and translocates the unfolded peptide into the ClpP chamber where proteolysis occurs. Substrate recognition involves the $\mathrm{N}$ - or C-terminal regions of the target protein binding to the substrate-processing site on ClpX $[111,112]$. These signals may become apparent after cleavage, as in the case of LexA, or upon a conformational change in the target protein $[113,114]$. However, the addition of an 11-amino acid (AANDENYALAA) ssrA tag to improperly translated nascent polypeptides will result in direct targeting to ClpXP for degradation [107, 108, 115118]. This C-terminal ssrA tag is encoded by the ssrA transfer mRNA and is added cotranslationally to proteins translated without an in-frame stop codon $[117,118]$. In addition, substrate recognition by ClpXP involves the interaction of tethering sites with adaptor proteins. These adaptor proteins are not degraded themselves but work to enhance the degradation of the target protein $[119,120]$. One example is the SspB-mediated degradation of ssrA-tagged protein. Here, one part of the target protein binds the tethering site on $\mathrm{ClpX}$ while the SspB protein interacts with the ssrA tag enabling efficient delivery to ClpXP for degradation [121, 122].

Similar to SspB-facilitated degradation of ssrA-tagged target proteins, UmuD' is a substrate for ClpXP but is only degraded when bound to full-length UmuD [123, 124]. Therefore, the preferential formation of UmuDD' heterodimer specifically leads to a decrease in the steadystate levels of UmuD' in vivo [123]. Although the residues found within the $\mathrm{N}$-terminal 24 amino acids of UmuD serve as the degradation signal for ClpXP degradation of UmuD', UmuD serves as an adaptor and is not itself degraded [124]. UmuD also serves as an adaptor in the context of
$\mathrm{UmuD}_{2}$ homodimers, leading to degradation of one $\mathrm{UmuD}$ in the dimer [123]. UmuD residues $9-12$ are necessary for $\mathrm{UmuD}^{\prime}$ instability and therefore protease recognition (Figure 3) [124]. Amino acids 15-19 of UmuD are also implicated in the degradation of the UmuDD' heterodimer by ClpXP (Figure 3) [124]. On the other hand, while residues 15-19 are also important for Lon-mediated degradation of UmuD, residues 9-12 are not involved in recognition by Lon [125]. ClpXP recognition sites can also be found on the surface of $\mathrm{UmuD}^{\prime}$, in particular, residues 33-37, 41-51, and 85-109 were found to interact robustly with ClpXP (Figure 3) [124]. The UmuD-facilitated degradation of UmuD' can be impeded by the SspB-tethering peptide, and the SspB-tethering motif is interchangeable with the sequence in UmuD. Because the N-terminal domain of ClpX mediates interactions with both $\mathrm{SspB}$ and UmuD, it was determined that UmuD acts as a ClpX delivery factor that is critical in tethering itself and $\mathrm{UmuD}^{\prime}$ to ClpX. This seems to be a primary mechanism for bringing SOS mutagenesis to an end [126].

\section{Conclusions}

Although the UmuD gene was discovered over 30 years ago, new findings regarding how the UmuD gene products regulate mutagenesis have been made even within the last few years. This is despite the fact that there is still no highresolution structure of full-length $\mathrm{UmuD}$. The extremely dynamic nature of UmuD and UmuD' has only recently come to light and provides insights into the large number of specific protein interactions of which the UmuD gene products are capable. Because of the role of UmuD in regulating mutagenesis, it could be important in bacterial evolution and is therefore potentially an important drug target.

\section{Acknowledgments}

Jaylene N. Ollivierre and Jing Fang contributed equally in this work. The authors are pleased to acknowledge generous financial support from a New Faculty Award from the Camille \& Henry Dreyfus Foundation (PJB), the NSF (CAREER Award, MCB-0845033 to PJB), and the NU Office of the Provost (PJB). P. J. Beuning is a Cottrell Scholar of the Research Corporation for Science Advancement.

\section{References}

[1] A. Bagg, C. J. Kenyon, and G. C. Walker, "Inducibility of a gene product required for UV and chemical mutagenesis in Escherichia coli," Proceedings of the National Academy of Sciences of the United States of America, vol. 78, no. 9, pp. 5749-5753, 1981.

[2] T. Kato and Y. Shinoura, "Isolation and characterization of mutants of Escherichia coli deficient in induction of mutations by ultraviolet light," Molecular and General Genetics, vol. 156, no. 2, pp. 121-131, 1977.

[3] G. Steinborn, "Uvm mutants of Escherichia coli K12 deficient in UV mutagenesis. I. Isolation of uvm mutants and their 
phenotypical characterization in DNA repair and mutagenesis," Molecular and General Genetics, vol. 165, no. 1, pp. 8793, 1978.

[4] E. C. Friedberg, G. C. Walker, W. Siede, R. D. Wood, R. A. Schultz, and T. Ellenberger, DNA Repair and Mutagenesis, ASM Press, Washington, DC, USA, 2nd edition, 2005.

[5] H. Ohmori, E. C. Friedberg, R. P. P. Fuchs et al., "The Yfamily of DNA polymerases," Molecular Cell, vol. 8, no. 1, pp. $7-8,2001$.

[6] D. F. Jarosz, P. J. Beuning, S. E. Cohen, and G. C. Walker, "Y-family DNA polymerases in Escherichia coli," Trends in Microbiology, vol. 15, no. 2, pp. 70-77, 2007.

[7] K. Schlacher and M. F. Goodman, "Lessons from 50 years of SOS DNA-damage-induced mutagenesis," Nature Reviews Molecular Cell Biology, vol. 8, no. 7, pp. 587-594, 2007.

[8] W. Yang and R. Woodgate, "What a difference a decade makes: insights into translesion DNA synthesis," Proceedings of the National Academy of Sciences of the United States of America, vol. 104, no. 40, pp. 15591-15598, 2007.

[9] A. Maor-Shoshani, N. B. Reuven, G. Tomer, and Z. Livneh, "Highly mutagenic replication by DNA polymerase V (UmuC) provides a mechanistic basis for SOS untargeted mutagenesis," Proceedings of the National Academy of Sciences of the United States of America, vol. 97, no. 2, pp. 565-570, 2000.

[10] S. D. McCulloch and T. A. Kunkel, "The fidelity of DNA synthesis by eukaryotic replicative and translesion synthesis polymerases," Cell Research, vol. 18, no. 1, pp. 148-161, 2008.

[11] S. Kobayashi, M. R. Valentine, P. Pham, M. O’Donnell, and M. F. Goodman, "Fidelity of Escherichia coli DNA polymerase IV: preferential generation of small deletion mutations by dNTP-stabilized misalignment," Journal of Biological Chemistry, vol. 277, no. 37, pp. 34198-34207, 2002.

[12] M. T. Washington, K. D. Carlson, B. D. Freudenthal, and J. M. Pryor, "Variations on a theme: eukaryotic Y-family DNA polymerases," Biochimica et Biophysica Acta, vol. 1804, no. 5, pp. 1113-1123, 2010.

[13] W. Yang, "Damage repair DNA polymerases Y," Current Opinion in Structural Biology, vol. 13, no. 1, pp. 23-30, 2003.

[14] W. Yang, "Portraits of a Y-family DNA polymerase," FEBS Letters, vol. 579, no. 4, pp. 868-872, 2005.

[15] J. Wagner, P. Gruz, S.-R. Kim et al., "The $\operatorname{dinB}$ gene encodes a novel E. coli DNA polymerase, DNA pol IV, involved in mutagenesis," Molecular Cell, vol. 4, no. 2, pp. 281-286, 1999.

[16] N. B. Reuven, G. Arad, A. Maor-Shoshani, and Z. Livneh, "The mutagenesis protein UmuC is a DNA polymerase activated by $\mathrm{UmuD}^{\prime}, \mathrm{RecA}$, and SSB and is specialized for translesion replication," Journal of Biological Chemistry, vol. 274, no. 45, pp. 31763-31766, 1999.

[17] M. Tang, X. Shen, E. G. Frank, M. O’Donnell, R. Woodgate, and M. F. Goodman, " $\mathrm{UmuD}_{2}^{\prime} \mathrm{C}$ is an error-prone DNA polymerase, Escherichia coli pol V," Proceedings of the National Academy of Sciences of the United States of America, vol. 96, no. 16, pp. 8919-8924, 1999.

[18] S. J. Elledge and G. C. Walker, "Proteins required for ultraviolet light and chemical mutagenesis: identification of the products of the umuC locus of Escherichia coli," Journal of Molecular Biology, vol. 164, no. 2, pp. 175-192, 1983.

[19] H. Shinagawa, T. Kato, T. Ise, K. Makino, and A. Nakata, "Cloning and characterization of the umu operon responsible for inducible mutagenesis in Escherichia coli," Gene, vol. 23, no. 2, pp. 167-174, 1983.
[20] L. A. Simmons, J. J. Foti, S. E. Cohen, and G. C. Walker, "The SOS regulatory network," in EcoSal-Escherichia coli and Salmonella: Cellular and Molecular Biology, A. Bock III, R. C. Kaper, J. B. Karp et al., Eds., chapter 5.4.3., ASM Press, Washington, DC, USA, 2008.

[21] J. Courcelle, A. Khodursky, B. Peter, P. O. Brown, and P. C. Hanawalt, "Comparative gene expression profiles following UV exposure in wild-type and SOS-deficient Escherichia coli," Genetics, vol. 158, no. 1, pp. 41-64, 2001.

[22] M. Sassanfar and J. W. Roberts, "Nature of the SOSinducing signal in Escherichia coli. The involvement of DNA replication," Journal of Molecular Biology, vol. 212, no. 1, pp. 79-96, 1990.

[23] J. W. Little, "Autodigestion of lexA and phage $\lambda$ repressors," Proceedings of the National Academy of Sciences of the United States of America, vol. 81, no. 3, pp. 1375-1379, 1984.

[24] S. B. Neher, J. M. Flynn, R. T. Sauer, and T. A. Baker, "Latent ClpX-recognition signals ensure LexA destruction after DNA damage," Genes and Development, vol. 17, no. 9, pp. 10841089, 2003.

[25] S.-R. Kim, K. Matsui, M. Yamada, P. Gruz, and T. Nohmi, "Roles of chromosomal and episomal dinB genes encoding DNA pol IV in targeted and untargeted mutagenesis in Escherichia coli," Molecular Genetics and Genomics, vol. 266, no. 2, pp. 207-215, 2001.

[26] R. Woodgate and D. G. Ennis, "Levels of chromosomally encoded Umu proteins and requirements for in vivo UmuD cleavage," Molecular and General Genetics, vol. 229, no. 1, pp. 10-16, 1991.

[27] T. Opperman, S. Murli, B. T. Smith, and G. C. Walker, "A model for a $u m u D C$-dependent prokaryotic DNA damage checkpoint," Proceedings of the National Academy of Sciences of the United States of America, vol. 96, no. 16, pp. 9218-9223, 1999.

[28] M. D. Sutton and G. C. Walker, "umuDC-mediated cold sensitivity is a manifestation of functions of the $\mathrm{UmuD}_{2} \mathrm{C}$ complex involved in a DNA damage checkpoint control," Journal of Bacteriology, vol. 183, no. 4, pp. 1215-1224, 2001.

[29] L. Marsh and G. C. Walker, "Cold sensitivity induced by overproduction of UmuDC in Escherichia coli," Journal of Bacteriology, vol. 162, no. 1, pp. 155-161, 1985.

[30] V. G. Godoy, D. F. Jarosz, S. M. Simon, A. Abyzov, V. Ilyin, and G. C. Walker, "UmuD and RecA directly modulate the mutagenic potential of the Y family DNA polymerase dinB," Molecular Cell, vol. 28, no. 6, pp. 1058-1070, 2007.

[31] H. Shinagawa, H. Iwasaki, T. Kato, and A. Nakata, "RecA protein-dependent cleavage of UmuD protein and SOS mutagenesis," Proceedings of the National Academy of Sciences of the United States of America, vol. 85, no. 6, pp. 1806-1810, 1988.

[32] T. Nohmi, J. R. Battista, L. A. Dodson, and G. C. Walker, "RecA-mediated cleavage activates UmuD for mutagenesis: mechanistic relationship between transcriptional derepression and posttranslational activation," Proceedings of the National Academy of Sciences of the United States of America, vol. 85, no. 6, pp. 1816-1820, 1988.

[33] S. E. Burckhardt, R. Woodgate, R. H. Scheuermann, and H. Echols, "UmuD mutagenesis protein of Escherichia coli: overproduction, purification, and cleavage by RecA," Proceedings of the National Academy of Sciences of the United States of America, vol. 85, no. 6, pp. 1811-1815, 1988. 
[34] M. Paetzel and N. C. J. Strynadka, "Common protein architecture and binding sites in proteases utilizing a Ser/Lys dyad mechanism," Protein Science, vol. 8, no. 11, pp. 25332536, 1999.

[35] S. N. Slilaty, J. A. Rupley, and J. W. Little, "Intramolecular cleavage of LexA and phage $\lambda$ repressors: dependence of kinetics on repressor concentration, $\mathrm{pH}$, temperature, and solvent," Biochemistry, vol. 25, no. 22, pp. 6866-6875, 1986.

[36] J. P. McDonald, T. S. Peat, A. S. Levine, and R. Woodgate, "Intermolecular cleavage by UmuD-like enzymes: identification of residues required for cleavage and substrate specificity," Journal of Molecular Biology, vol. 285, no. 5, pp. 2199-2209, 1999.

[37] J. P. McDonald, E. G. Frank, A. S. Levine, and R. Woodgate, "Intermolecular cleavage by UmuD-like mutagenesis proteins," Proceedings of the National Academy of Sciences of the United States of America, vol. 95, no. 4, pp. 1478-1483, 1998.

[38] J. P. McDonald, E. E. Maury, A. S. Levine, and R. Woodgate, "Regulation of UmuD cleavage: role of the amino-terminal tail," Journal of Molecular Biology, vol. 282, no. 4, pp. 721730, 1998.

[39] I. Bruck, R. Woodgate, K. McEuntee, and M. F. Goodman, "Purification of a soluble UmuD' C complex from Escherichia coli: cooperative binding of $\mathrm{UmuD}^{\prime} \mathrm{C}$ to single-stranded DNA," Journal of Biological Chemistry, vol. 271, no. 18, pp. 10767-10774, 1996.

[40] R. Woodgate, M. Rajagopalan, C. Lu, and H. Echols, "UmuC mutagenesis protein of Escherichia coli: purification and interaction with $\mathrm{UmuD}$ and $\mathrm{UmuD}^{\prime}$," Proceedings of the National Academy of Sciences of the United States of America, vol. 86, no. 19, pp. 7301-7305, 1989.

[41] W. M. Rehrauer, P. E. Lavery, E. L. Palmer, R. N. Singh, and S. C. Kowalczykowskit, "Interaction of Escherichia coli RecA protein with LexA repressor. I. LexA repressor cleavage is competitive with binding of a secondary DNA molecule," Journal of Biological Chemistry, vol. 271, no. 39, pp. 2386523873, 1996.

[42] S. Sommer, A. Bailone, and R. Devoret, "The appearance of the UmuD'C protein complex in Escherichia coli switches repair from homologous recombination to SOS mutagenesis," Molecular Microbiology, vol. 10, no. 5, pp. 963-971, 1993.

[43] H. Szpilewska, P. Bertrand, A. Bailone, and M. Dutreix, "In vitro inhibition of RecA-mediated homologous pairing by UmuD'C proteins," Biochimie, vol. 77, no. 11, pp. 848-853, 1995.

[44] A. E. Ferentz, G. C. Walker, and G. Wagner, "Converting a DNA damage checkpoint effector $\left(\mathrm{UmuD}_{2} \mathrm{C}\right)$ into a lesion bypass polymerase $\left(\mathrm{UmuD}_{2}^{\prime} \mathrm{C}\right)$," EMBO Journal, vol. 20, no. 15, pp. 4287-4298, 2001.

[45] A. E. Ferentz, T. Opperman, G. C. Walker, and G. Wagner, "Dimerization of the UmuD' protein in solution and its implications for regulation of SOS mutagenesis," Nature Structural Biology, vol. 4, no. 12, pp. 979-983, 1997.

[46] T. S. Peat, E. G. Frank, J. P. McDonald, A. S. Levine, R. Woodgate, and W. A. Hendrickson, "Structure of the UmuD' protein and its regulation in response to DNA damage," Nature, vol. 380, no. 6576, pp. 727-730, 1996.

[47] M. D. Sutton, A. Guzzo, I. Narumi et al., "A model for the structure of the Escherichia coli SOS-regulated $\mathrm{UmuD}_{2}$ protein," DNA Repair, vol. 1, no. 1, pp. 77-93, 2002.

[48] S. M. Simon, F. J. R. Sousa, R. Mohana-Borges, and G. C. Walker, "Regulation of Escherichia coli SOS mutagenesis by dimeric intrinsically disordered $u m u D$ gene products,"
Proceedings of the National Academy of Sciences of the United States of America, vol. 105, no. 4, pp. 1152-1157, 2008.

[49] M. H. Lee and G. C. Walker, "Interactions of Escherichia coli UmuD with activated RecA analyzed by cross-linking UmuD monocysteine derivatives," Journal of Bacteriology, vol. 178, no. 24, pp. 7285-7294, 1996.

[50] E. G. Frank, N. Cheng, C. C. Do et al., "Visualization of two binding sites for the Escherichia coli $\mathrm{UmuD}_{2}^{\prime} \mathrm{C}$ complex (DNA pol V) on RecA-ssDNA filaments," Journal of Molecular Biology, vol. 297, no. 3, pp. 585-597, 2000.

[51] J. Fang, K. D. Rand, M. C. Silva, T. E. Wales, J. R. Engen, and P. J. Beuning, "Conformational dynamics of the Escherichia coli DNA polymerase manager proteins UmuD and UmuD'," Journal of Molecular Biology, vol. 398, no. 1, pp. 40-53, 2010.

[52] P. J. Beuning, S. M. Simon, A. Zemla, D. Barsky, and G. C. Walker, "A non-cleavable UmuD variant that acts as a UmuD' mimic," Journal of Biological Chemistry, vol. 281, no. 14, pp. 9633-9640, 2006.

[53] M. D. Sutton, I. Narumi, and G. C. Walker, "Posttranslational modification of the umuD-encoded subunit of Escherichia coli DNA polymerase $\mathrm{V}$ regulates its interactions with the $\beta$ processivity clamp," Proceedings of the National Academy of Sciences of the United States of America, vol. 99, no. 8, pp. 5307-5312, 2002.

[54] M. D. Sutton, M. Kim, and G. C. Walker, "Genetic and biochemical characterization of a novel umuD mutation: insights into a mechanism for UmuD self-cleavage," Journal of Bacteriology, vol. 183, no. 1, pp. 347-357, 2001.

[55] J. R. Battista, T. Ohta, T. Nohmi, W. Sun, and G. C. Walker, "Dominant negative umuD mutations decreasing RecA-mediated cleavage suggest roles for intact UmuD in modulation of SOS mutagenesis," Proceedings of the National Academy of Sciences of the United States of America, vol. 87, no. 18, pp. 7190-7194, 1990.

[56] T. S. Peat, E. G. Frank, J. P. McDonald, A. S. Levine, R. Woodgate, and W. A. Hendrickson, "The UmuD' protein filament and its potential role in damage induced mutagenesis," Structure, vol. 4, no. 12, pp. 1401-1412, 1996.

[57] Z. Kelman and M. O’Donnell, "DNA polymerase III holoenzyme: structure and function of a chromosomal replicating machine," Annual Review of Biochemistry, vol. 64, pp. 171200, 1995.

[58] C. S. McHenry, "Chromosomal replicases as asymmetric dimers: studies of subunit arrangement and functional consequences," Molecular Microbiology, vol. 49, no. 5, pp. 1157-1165, 2003.

[59] S. Fujii, V. Gasser, and R. P. Fuchs, "The biochemical requirements of DNA polymerase V-mediated translesion synthesis revisited," Journal of Molecular Biology, vol. 341, no. 2, pp. 405-417, 2004.

[60] S. Fujii, A. Isogawa, and R. P. Fuchs, "RecFOR proteins are essential for Pol V-mediated translesion synthesis and mutagenesis," EMBO Journal, vol. 25, no. 24, pp. 5754-5763, 2006.

[61] M. D. Sutton, T. Opperman, and G. C. Walker, "The Escherichia coli SOS mutagenesis proteins UmuD and UmuD' interact physically with the replicative DNA polymerase," Proceedings of the National Academy of Sciences of the United States of America, vol. 96, no. 22, pp. 12373-12378, 1999.

[62] M. D. Sutton, S. Murli, T. Opperman, C. Klein, and G. C. Walker, "umuDC-dnaQ interaction and its implications for cell cycle regulation and SOS mutagenesis in Escherichia coli," Journal of Bacteriology, vol. 183, no. 3, pp. 1085-1089, 2001. 
[63] S. A. Taft-Benz and R. M. Schaaper, "The C-terminal domain of DnaQ contains the polymerase binding site," Journal of Bacteriology, vol. 181, no. 9, pp. 2963-2965, 1999.

[64] M. D. Sutton, M. F. Farrow, B. M. Burton, and G. C. Walker, "Genetic interactions between the Escherichia coli umuDC gene products and the $\beta$ processivity clamp of the replicative DNA polymerase," Journal of Bacteriology, vol. 183, no. 9, pp. 2897-2909, 2001.

[65] P. J. Beuning, S. Chan, L. S. Waters, H. Addepalli, J. N. Ollivierre, and G. C. Walker, "Characterization of novel alleles of the Escherichia coli umuDC genes identifies additional interaction sites of UmuC with the beta clamp," Journal of Bacteriology, vol. 191, no. 19, pp. 5910-5920, 2009.

[66] J. M. Duzen, G. C. Walker, and M. D. Sutton, "Identification of specific amino acid residues in the E. coli $\beta$ processivity clamp involved in interactions with DNA polymerase III, UmuD and UmuD'," DNA Repair, vol. 3, no. 3, pp. 301-312, 2004.

[67] B. P. Dalrymple, K. Kongsuwan, G. Wijffels, N. E. Dixon, and P. A. Jennings, "A universal protein-protein interaction motif in the eubacterial DNA replication and repair systems," Proceedings of the National Academy of Sciences of the United States of America, vol. 98, no. 20, pp. 11627-11632, 2001.

[68] D. Y. Burnouf, V. Olieric, J. Wagner et al., "Structural and biochemical analysis of sliding clamp/ligand interactions suggest a competition between replicative and translesion DNA polymerases," Journal of Molecular Biology, vol. 335, no. 5, pp. 1187-1197, 2004.

[69] J. M. H. Heltzel, R. W. Maul, S. K. Scouten Ponticelli, and M. D. Sutton, "A model for DNA polymerase switching involving a single cleft and the rim of the sliding clamp," Proceedings of the National Academy of Sciences of the United States of America, vol. 106, no. 31, pp. 12664-12669, 2009.

[70] J. M. H. Heltzel, S. K. Scouten Ponticelli, L. H. Sanders et al., "Sliding clamp-DNA interactions are required for viability and contribute to DNA polymerase management in Escherichia coli," Journal of Molecular Biology, vol. 387, no. 1, pp. 74-91, 2009.

[71] R. W. Maul, S. K. Scouten Ponticelli, J. M. Duzen, and M. D. Sutton, "Differential binding of Escherichia coli DNA polymerases to the $\beta$-sliding clamp," Molecular Microbiology, vol. 65, no. 3, pp. 811-827, 2007.

[72] S. K. Scouten Ponticelli, J. M. Duzen, and M. D. Sutton, "Contributions of the individual hydrophobic clefts of the Escherichia coli $\beta$ sliding clamp to clamp loading, DNA replication and clamp recycling," Nucleic Acids Research, vol. 37, no. 9, pp. 2796-2809, 2009.

[73] M. D. Sutton and J. M. Duzen, "Specific amino acid residues in the $\beta$ sliding clamp establish a DNA polymerase usage hierarchy in Escherichia coli," DNA Repair, vol. 5, no. 3, pp. 312-323, 2006.

[74] G. Wijffels, B. P. Dalrymple, P. Prosselkov et al., "Inhibition of protein interactions with the $\beta_{2}$ sliding clamp of Escherichia coli DNA polymerase III by peptides from $\beta_{2}$-binding proteins," Biochemistry, vol. 43, no. 19, pp. 5661-5671, 2004.

[75] M. Tang, P. Pham, X. Shen et al., "Roles of E. coli DNA polymerases IV and V in lesion-targeted and untargeted SOS mutagenesis," Nature, vol. 404, no. 6781, pp. 1014-1018, 2000.

[76] L. B. Bloom, X. Chen, D. K. Fygenson, J. Turner, M. O'Donnell, and M. F. Goodman, "Fidelity of Escherichia coli DNA polymerase III holoenzyme: the effects of $\beta, \gamma$ complex processivity proteins and $\varepsilon$ proofreading exonuclease on nucleotide misincorporation efficiencies," Journal of Biological Chemistry, vol. 272, no. 44, pp. 27919-27930, 1997.

[77] N. B. Reuven, G. Tomer, and Z. Livneh, "The mutagenesis proteins UmuD' and UmuC prevent lethal frameshifts while increasing base substitution mutations," Molecular Cell, vol. 2, no. 2, pp. 191-199, 1998.

[78] S. Fujii and R. P. Fuchs, "Defining the position of the switches between replicative and bypass DNA polymerases," EMBO Journal, vol. 23, no. 21, pp. 4342-4352, 2004.

[79] O. J. Becherel and R. P. P. Fuchs, "SOS mutagenesis results from up-regulation of translesion synthesis," Journal of Molecular Biology, vol. 294, no. 2, pp. 299-306, 1999.

[80] K. Schlacher, K. Leslie, C. Wyman, R. Woodgate, M. M. Cox, and M. F. Goodman, "DNA polymerase V and RecA protein, a minimal mutasome," Molecular Cell, vol. 17, no. 4, pp. 561572, 2005.

[81] K. Schlacher, M. M. Cox, R. Woodgate, and M. F. Goodman, "RecA acts in trans to allow replication of damaged DNA by DNA polymerase V," Nature, vol. 442, no. 7105, pp. 883-887, 2006.

[82] A. Maor-Shoshani and Z. Livneh, "Analysis of the stimulation of DNA polymerase $\mathrm{V}$ of Escherichia coli by processivity proteins," Biochemistry, vol. 41, no. 48, pp. 14438-14446, 2002.

[83] N. B. Reuven, G. Arad, A. Z. Stasiak, A. Stasiak, and Z. Livneh, "Lesion bypass by the Escherichia coli DNA polymerase $\mathrm{V}$ requires assembly of a RecA nucleoprotein filament," Journal of Biological Chemistry, vol. 276, no. 8, pp. 5511-5517, 2001.

[84] P. Pham, E. M. Seitz, S. Saveliev et al., "Two distinct modes of RecA action are required for DNA polymerase V-catalyzed translesion synthesis," Proceedings of the National Academy of Sciences of the United States of America, vol. 99, no. 17, pp. 11061-11066, 2002.

[85] Q. Jiang, K. Karata, R. Woodgate, M. M. Cox, and M. F. Goodman, “The active form of DNA polymerase $\mathrm{v}$ is UmuD' 2 C-RecA-ATP,” Nature, vol. 460, no. 7253, pp. 359-363, 2009.

[86] G. Arad, A. Hendel, C. Urbanke, U. Curth, and Z. Livneh, "Single-stranded DNA-binding protein recruits DNA polymerase $\mathrm{V}$ to primer termini on RecA-coated DNA," Journal of Biological Chemistry, vol. 283, no. 13, pp. 8274-8282, 2008.

[87] M. Rajagopalan, C. Lu, R. Woodgate, M. O’Donnell, M. F. Goodman, and H. Echols, "Activity of the purified mutagenesis proteins $\mathrm{UmuC}, \mathrm{UmuD}^{\prime}$, and RecA in replicative bypass of an abasic DNA lesion by DNA polymerase III," Proceedings of the National Academy of Sciences of the United States of America, vol. 89, no. 22, pp. 10777-10781, 1992.

[88] R. Woodgate, M. Rajagopalan, C. Lu, and H. Echols, "UmuC mutagenesis protein of Escherichia coli: purification and interaction with $\mathrm{UmuD}$ and $\mathrm{UmuD}^{\prime}$," Proceedings of the National Academy of Sciences of the United States of America, vol. 86, no. 19, pp. 7301-7305, 1989.

[89] P. Jonczyk and A. Nowicka, "Specific in vivo protein-protein interactions between Escherichia coli SOS mutagenesis proteins," Journal of Bacteriology, vol. 178, no. 9, pp. 2580-2585, 1996.

[90] M. Rajagopalan, C. Lu, R. Woodgate, M. O’Donnell, M. F. Goodman, and H. Echols, "Activity of the purified mutagenesis proteins UmuC, $\mathrm{UmuD}^{\prime}$, and RecA in replicative bypass of an abasic DNA lesion by DNA polymerase III," Proceedings of the National Academy of Sciences of the United States of America, vol. 89, no. 22, pp. 10777-10781, 1992. 
[91] I. Bruck, R. Woodgate, K. McEuntee, and M. F. Goodman, "Purification of a soluble UmuD' C complex from Escherichia coli: cooperative binding of $\mathrm{UmuD}^{\prime} \mathrm{C}$ to single-stranded DNA," Journal of Biological Chemistry, vol. 271, no. 18, pp. 10767-10774, 1996.

[92] C. J. Kenyon and G. C. Walker, "DNA-damaging agents stimulate gene expression at specific loci in Escherichia coli," Proceedings of the National Academy of Sciences of the United States of America, vol. 77, no. 5, pp. 2819-2823, 1980.

[93] B. S. Strauss, R. Roberts, L. Francis, and P. Pouryazdanparast, "Role of the $\operatorname{din} B$ gene product in spontaneous mutation in Escherichia coli with an impaired replicative polymerase," Journal of Bacteriology, vol. 182, no. 23, pp. 6742-6750, 2000.

[94] S. Kobayashi, M. R. Valentine, P. Pham, M. O’Donnell, and M. F. Goodman, "Fidelity of Escherichia coli DNA polymerase IV. Preferential generation of small deletion mutations by dNTP-stabilized misalignment," Journal of Biological Chemistry, vol. 277, no. 37, pp. 34198-34207, 2002.

[95] J. Wagner, P. Gruz, S.-R. Kim et al., "The $\operatorname{dinB}$ gene encodes a novel E. coli DNA polymerase, DNA pol IV, involved in mutagenesis," Molecular Cell, vol. 4, no. 2, pp. 281-286, 1999.

[96] S.-R. Kim, K. Matsui, M. Yamada, P. Gruz, and T. Nohmi, "Roles of chromosomal and episomal $\operatorname{din} B$ genes encoding DNA pol IV in targeted and untargeted mutagenesis in Escherichia coli," Molecular Genetics and Genomics, vol. 266, no. 2, pp. 207-215, 2001.

[97] D. F. Jarosz, V. G. Godoy, J. C. Delaney, J. M. Essigmann, and G. C. Walker, "A single amino acid governs enhanced activity of dinB DNA polymerases on damaged templates," Nature, vol. 439, no. 7073, pp. 225-228, 2006.

[98] R. Napolitano, R. Janel-Bintz, J. Wagner, and R. P. P. Fuchs, "All three SOS-inducible DNA polymerases (Pol II, Pol IV and Pol V) are involved in induced mutagenesis," EMBO Journal, vol. 19, no. 22, pp. 6259-6265, 2000.

[99] N. Lenne-Samuel, R. Janel-Bintz, A. Kolbanovskiy, N. E. Geacintov, and R. P. P. Fuchs, "The processing of a Benzo(a)pyrene adduct into a frameshift or a base substitution mutation requires a different set of genes in Escherichia coli," Molecular Microbiology, vol. 38, no. 2, pp. 299-307, 2000.

[100] J. J. Foti, A. M. DeLucia, C. M. Joyce, and G. C. Walker, "UmuD $\mathrm{D}_{2}$ inhibits a non-covalent step during $\operatorname{din} B$-mediated template slippage on homopolymeric nucleotide runs," Journal of Biological Chemistry, vol. 285, no. 30, pp. 23086-23095, 2010.

[101] P. J. Beuning, S. M. Simon, V. G. Godoy, D. F. Jarosz, and G. C. Walker, "Characterization of Escherichia coli translesion synthesis polymerases and their accessory factors," Methods in Enzymology, vol. 408, pp. 318-340, 2006.

[102] H. Ling, F. Boudsocq, R. Woodgate, and W. Yang, "Crystal structure of a Y-family DNA polymerase in action: a mechanism for error-prone and lesion-bypass replication," Cell, vol. 107, no. 1, pp. 91-102, 2001.

[103] M. Gonzalez and R. Woodgate, "The "tale" of umuD and its role in SOS mutagenesis," BioEssays, vol. 24, no. 2, pp. 141$148,2002$.

[104] E. G. Frank, D. G. Ennis, M. Gonzalez, A. S. Levine, and R. Woodgate, "Regulation of SOS mutagenesis by proteolysis," Proceedings of the National Academy of Sciences of the United States of America, vol. 93, no. 19, pp. 10291-10296, 1996.

[105] S. Gottesman, W. P. Clark, V. De Crecy-Lagard, and M. R. Maurizi, "ClpX, an alternative subunit for the ATPdependent Clp protease of Escherichia coli. Sequence and in vivo activities," Journal of Biological Chemistry, vol. 268, no. 30, pp. 22618-22626, 1993.

[106] M. R. Maurizi, W. P. Clark, Y. Katayama et al., "Sequence and structure of Clp P, the proteolytic component of the ATP-dependent Clp protease of Escherichia coli," Journal of Biological Chemistry, vol. 265, no. 21, pp. 12536-12545, 1990.

[107] Y.-I. Kim, R. E. Burton, B. M. Burton, R. T. Sauer, and T. A. Baker, "Dynamics of substrate denaturation and translocation by the ClpXP degradation machine," Molecular Cell, vol. 5, no. 4, pp. 639-648, 2000.

[108] S. K. Singh, R. Grimaud, J. R. Hoskins, S. Wickner, and M. R. Maurizi, "Unfolding and internalization of proteins by the ATP-dependent proteases ClpXP and ClpAP," Proceedings of the National Academy of Sciences of the United States of America, vol. 97, no. 16, pp. 8898-8903, 2000.

[109] J. Wang, J. A. Hartling, and J. M. Flanagan, "The structure of ClpP at $2.3 \AA$ resolution suggests a model for ATP-dependent proteolysis," Cell, vol. 91, no. 4, pp. 447-456, 1997.

[110] C. K. Smith, T. A. Baker, and R. T. Sauer, "Lon and Clp family proteases and chaperones share homologous substrate-recognition domains," Proceedings of the National Academy of Sciences of the United States of America, vol. 96, no. 12, pp. 6678-6682, 1999.

[111] M. Gonciarz-Swiatek, A. Wawrzynow, S.-J. Um et al., "Recognition, targeting, and hydrolysis of the $\lambda \mathrm{O}$ replication protein by the ClpP/ClpX protease," Journal of Biological Chemistry, vol. 274, no. 20, pp. 13999-14005, 1999.

[112] J. M. Flynn, S. B. Neher, Y.-I. Kim, R. T. Sauer, and T. A. Baker, "Proteomic discovery of cellular substrates of the ClpXP protease reveals five classes of ClpX-recognition signals," Molecular Cell, vol. 11, no. 3, pp. 671-683, 2003.

[113] K. R. Marshall-Batty and H. Nakai, "trans-targeting of the phage $\mathrm{Mu}$ repressor is promoted by conformational changes that expose its ClpX recognition determinant," Journal of Biological Chemistry, vol. 278, no. 3, pp. 1612-1617, 2003.

[114] S. B. Neher, J. M. Flynn, R. T. Sauer, and T. A. Baker, "Latent ClpX-recognition signals ensure LexA destruction after DNA damage," Genes and Development, vol. 17, no. 9, pp. 10841089, 2003.

[115] B. M. Burton, T. L. Williams, and T. A. Baker, "ClpXmediated remodeling of $\mathrm{Mu}$ transpososomes: selective unfolding of subunits destabilizes the entire complex," Molecular Cell, vol. 8, no. 2, pp. 449-454, 2001.

[116] J. A. Kenniston, T. A. Baker, J. M. Fernandez, and R. T. Sauer, "Linkage between ATP consumption and mechanical unfolding during the protein processing reactions of an AAA+ degradation machine," Cell, vol. 114, no. 4, pp. 511520, 2003.

[117] A. W. Karzai, E. D. Roche, and R. T. Sauer, "The SsrASmpB system for protein tagging, directed degradation and ribosome rescue," Nature Structural Biology, vol. 7, no. 6, pp. 449-455, 2000.

[118] D. Dulebohn, J. Choy, T. Sundermeier, N. Okan, and A. W. Karzai, "Trans-translation: the tmRNA-mediated surveillance mechanism for ribosome rescue, directed protein degradation, and nonstop mRNA decay," Biochemistry, vol. 46, no. 16, pp. 4681-4693, 2007.

[119] I. Levchenko, R. A. Grant, D. A. Wah, R. T. Sauer, and T. A. Baker, "Structure of a delivery protein for an AAA+ protease in complex with a peptide degradation tag," Molecular Cell, vol. 12, no. 2, pp. 365-372, 2003.

[120] I. Levchenko, M. Seidel, R. T. Sauer, and T. A. Baker, "A specificity-enhancing factor for the ClpXP degradation machine," Science, vol. 289, no. 5488, pp. 2354-2356, 2000. 
[121] D. A. Wah, I. Levchenko, T. A. Baker, and R. T. Sauer, "Characterization of a specificity factor for an AAA+ ATPase: assembly of SspB dimers with ssrA-tagged proteins and the ClpX hexamer," Chemistry and Biology, vol. 9, no. 11, pp. 1237-1245, 2002.

[122] D. A. Wah, I. Levchenko, G. E. Rieckhof, D. N. Bolon, T. A. Baker, and R. T. Sauer, "Flexible linkers leash the substrate binding domain of SspB to a peptide module that stabilizes delivery complexes with the AAA+ ClpXP protease," Molecular Cell, vol. 12, no. 2, pp. 355-363, 2003.

[123] S. B. Neher, R. T. Sauer, and T. A. Baker, "Distinct peptide signals in the $\mathrm{UmuD}$ and $\mathrm{UmuD}^{\prime}$ subunits of $\mathrm{UmuD} / \mathrm{D}^{\prime}$ mediate tethering and substrate processing by the ClpXP protease," Proceedings of the National Academy of Sciences of the United States of America, vol. 100, no. 23, pp. 1321913224, 2003.

[124] M. Gonzalez, F. Rasulova, M. R. Maurizi, and R. Woodgate, "Subunit-specific degradation of the UmuD/D' heterodimer by the ClpXP protease: the role of trans recognition in UmuD' stability," EMBO Journal, vol. 19, no. 19, pp. 5251$5258,2000$.

[125] M. Gonzalez, E. G. Frank, A. S. Levine, and R. Woodgate, "Lon-mediated proteolysis of the Escherichia coli UmuD mutagenesis protein: in vitro degradation and identification of residues required for proteolysis," Genes and Development, vol. 12, no. 24, pp. 3889-3899, 1998.

[126] M. D. Sutton, "Damage signals triggering the Escherichia coli SOS response," in DNA Damage and Recognition, Y. W. K. Wolfram Seide and P. W. Doetsch, Eds., pp. 781-802, Taylor \& Francis, New York, NY, USA, 2006.

[127] O. J. Becherel, R. P. P. Fuchs, and J. Wagner, "Pivotal role of the $\beta$-clamp in translesion DNA synthesis and mutagenesis in E. coli cells," DNA Repair, vol. 1, no. 9, pp. 703-708, 2002.

[128] P. J. Beuning, D. Sawicka, D. Barsky, and G. C. Walker, "Two processivity clamp interactions differentially alter the dual activities of UmuC," Molecular Microbiology, vol. 59, no. 2, pp. 460-474, 2006.

[129] K. A. Bunting, S. M. Roe, and L. H. Pearl, "Structural basis for recruitment of translesion DNA polymerase Pol IV/dinB to the $\beta$-clamp," EMBO Journal, vol. 22, no. 21, pp. 58835892, 2003.

[130] P. R. Dohrmann and C. S. McHenry, "A bipartite polymeraseprocessivity factor interaction: only the internal $\beta$ binding site of the $\alpha$ subunit is required for processive replication by the DNA polymerase III holoenzyme," Journal of Molecular Biology, vol. 350, no. 2, pp. 228-239, 2005.

[131] D. Jeruzalmi, O. Yurieva, Y. Zhao et al., "Mechanism of processivity clamp opening by the delta subunit wrench of the clamp loader complex of E. coli DNA polymerase III," Cell, vol. 106, no. 4, pp. 417-428, 2001.

[132] F. J. López de Saro and M. O’Donnell, "Interaction of the $\beta$ sliding clamp with MutS, ligase, and DNA polymerase I," Proceedings of the National Academy of Sciences of the United States of America, vol. 98, no. 15, pp. 8376-8380, 2001.

[133] M. Kurz, B. Dalrymple, G. Wijffels, and K. Kongsuwan, "Interaction of the sliding clamp $\beta$-subunit and $\mathrm{Hda}$, a DnaA-related protein," Journal of Bacteriology, vol. 186, no. 11, pp. 3508-3515, 2004. 

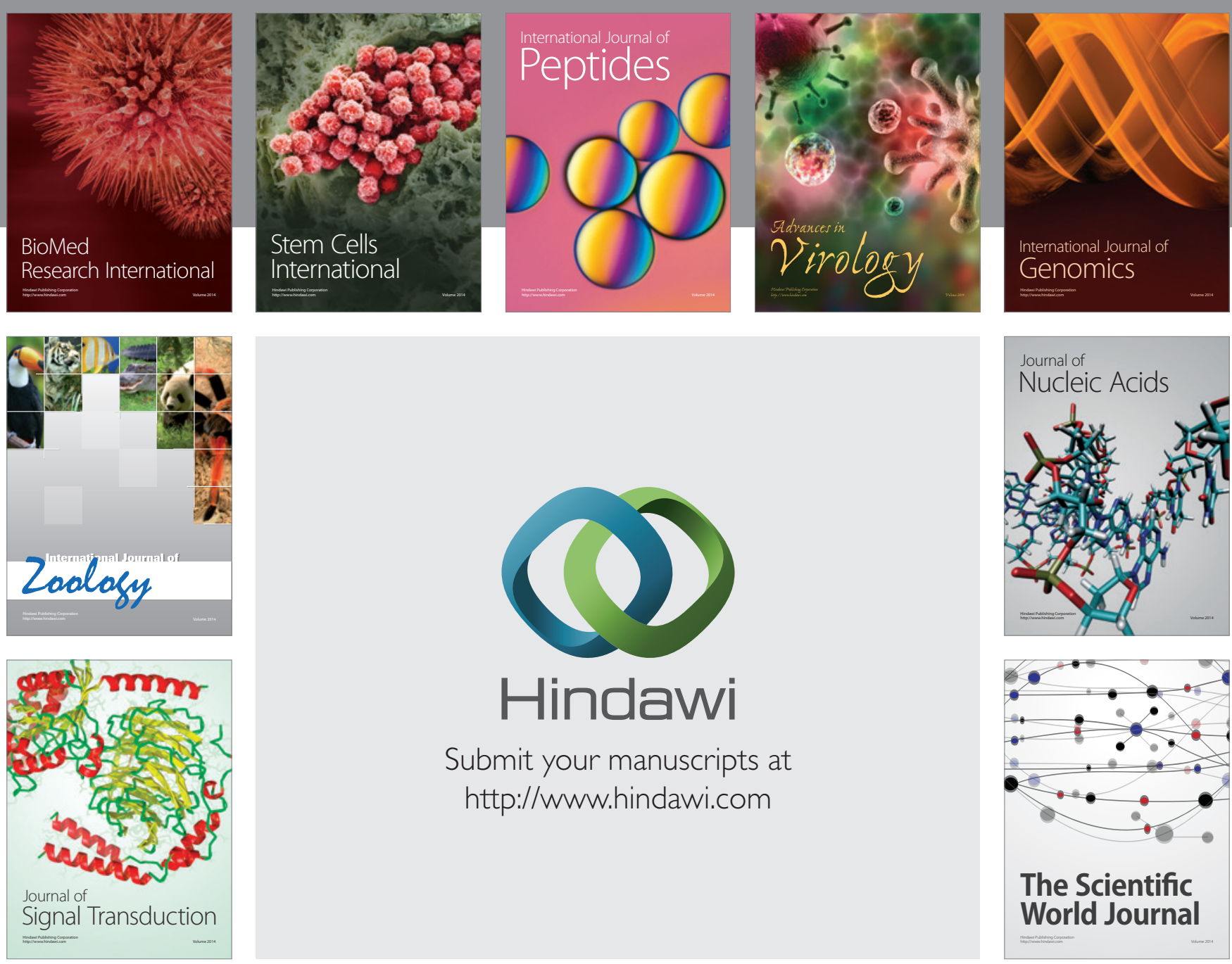

Submit your manuscripts at

http://www.hindawi.com
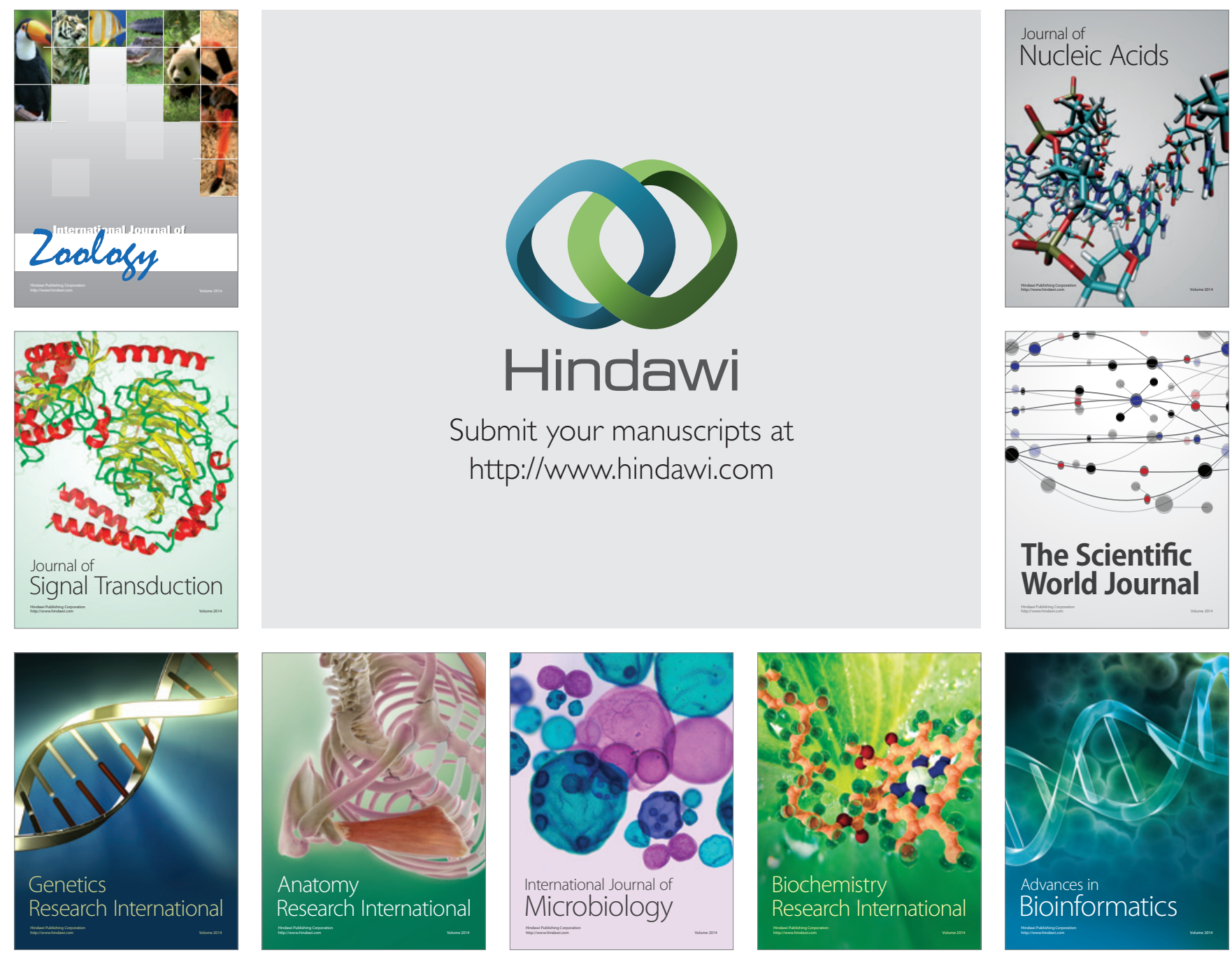

The Scientific World Journal
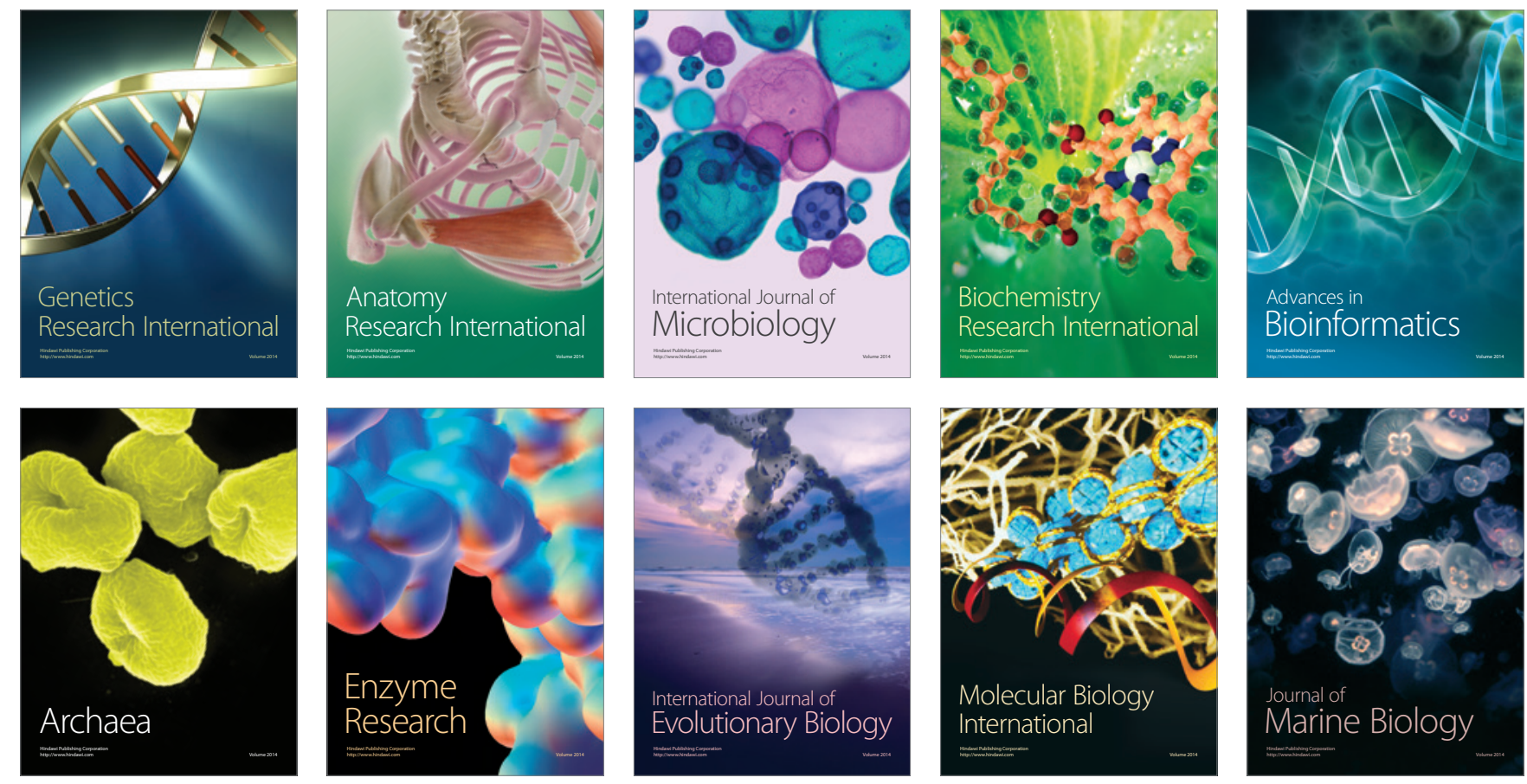